\title{
Efeito da ordem de parição e do período de ordenha na produção e composição do colostro e do leite de transição de cabras Saanen
}

\section{Ana Letícia Tôrres Vilar ${ }^{1}$, Roberto Germano Costa ${ }^{2}$, Patrício Marques de Souza ${ }^{3}$, Ariosvaldo Nunes de Medeiros ${ }^{4}$, Rita de Cássia Ramos do Egypto Queiroga ${ }^{5}$, Marcelo Ferreira Fernandes $^{6}$}

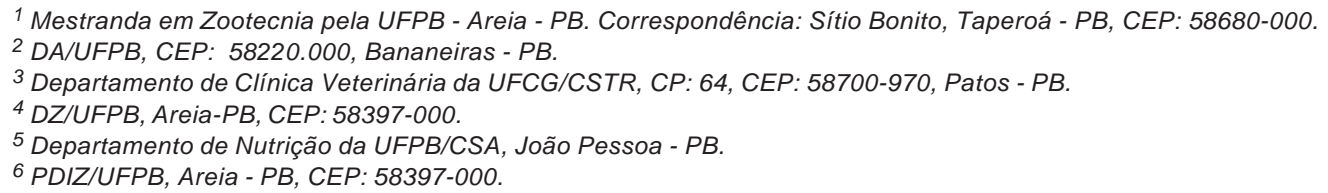

RESUMO - Com o objetivo de verificar a influência da ordem de parto e do período da ordenha na produção e composição físico-química do colostro e do leite de transição de cabras Saanen, utilizaram-se três grupos de animais (16 animais de primeira parição; 17 animais de segunda parição e oito animais de terceira ou mais parições) e coletaram-se amostras nos horários de 0, 8, 12 e 24 horas após o parto. A ordem de parto não influenciou a produção do colostro e leite de transição e não afetou significativamente as características estudadas (acidez, densidade, gordura, extrato seco total e proteína total), com exceção do $\mathrm{pH}$, que diferiu significativamente $(6,70 ; 6,50$ e 6,46) entre os animais de terceira, mais de primeira e segunda parições, respectivamente. O período da ordenha influenciou os teores de gordura (8,29 e 5,14\%), extrato seco total (10,52 e 6,68\%), proteína total $(9,24$ e $4,37 \%)$ e acidez $\left(46,1\right.$ e $\left.25,1^{\circ} \mathrm{D}\right)$ nos períodos de 0 e 24 horas pós-parto, respectivamente. A ordem de parto não influencia a produção nem a composição físico-química das secreções lácteas de fêmeas caprinas nas primeiras 24 horas após o parto, com exceção do pH.

Palavras-chave: acidez, caprinos, físico-química, gordura, proteína total

\section{Effect of parturition order and milking time in the composition and production of the colostrum and transition milk of Saanen goats}

\begin{abstract}
Aiming to study the influence of parturition order and milking time in the production and physical-chemical composition of colostrum and transition milk secretion of Saanen goats, three groups of animals were used (16 from the first parturition; 17 from the second and 8 from the third or more parturitions) and samples were collected at zero, 12 and $24 \mathrm{~h}$ after kidding. Parturition order did not interfere in colostrum and transition milk secretion productions, neither in the studied characteristics (acidity, density, fat, total dry extract and total protein), except for $\mathrm{pH}$, which differ $(6.70$; 6.50; 6.46) among goats of $3^{\text {rd }}$ or more, $1^{\text {st }}$ and $2^{\text {nd }}$ parturition, respectively. Milking time influenced fat contents (8.29 and 5.14\%); total dry extract (10.52 and 6.68\%); total protein (9.24 and 4.37\%); acidity $\left(46.1\right.$ and $\left.25.1^{\circ} \mathrm{D}\right)$ in the period from 0 and $24 \mathrm{~h}$ post kidding, respectively. Parturition order did not affected milky secretion production and physical-chemical composition in the first 24 hours post kidding, except for $\mathrm{pH}$.
\end{abstract}

Key Words: acidity, fat, goat, physical-chemical, total protein

\section{Introdução}

As primeiras 24 horas de vida são o período de maior importância para o reconhecimento de situações que possam gerar problemas de saúde no neonato. Intervenções oportunas nesta fase podem diminuir as conseqüências negativas à higidez e à produtividade dos animais (Feitosa et al., 2001).
Imediatamente após o nascimento, os neonatos são expostos a uma variedade de agentes infecciosos presentes no ambiente e podem adoecer e morrer. Portanto, dependem de anticorpos para neutralizar substâncias antigênicas invasoras que atacam o organismo. O colostro, mais que uma fonte de anticorpos, fornece nutrientes importantes e necessários ao metabolismo e crescimento (Lazzaro, 2002). 
O benefício nutritivo do colostro na alimentação animal é freqüentemente negligenciado, sobretudo quando se considera a exigência de energia do recém-nascido. O colostro fornece níveis elevados de gordura e de lactose, críticos para manutenção da temperatura do corpo, fundamental nos períodos frios (Waterman, 1998).

Diversos fatores, como raça, estágio de lactação, alimentação e condições ambientais, afetam as características físico-químicas do colostro. Durante as primeiras quatro ordenhas após o parto, ocorrem as principais mudanças na composição da secreção láctea; a lactose aumenta, enquanto os teores de proteína, gordura, sólidos totais e cinzas decrescem (Parrish et al., 1950).

De acordo com Argüello et al. (2006), as características químicas e físicas do colostro são influenciadas pelo tempo pós-parto e pelo número de lactações. Informações similares foram encontradas por Chen et al. (1998), que verificaram diminuição dos níveis de proteína total e globulina do leite nas primeiras 24 horas após o parto.

O desenvolvimento de pesquisas para obtenção de informações sobre parâmetros físicos e químicos do colostro caprino e sobre os fatores que influenciam sua qualidade é necessário, tendo em vista a importância do colostro na nutrição e prevenção contra enfermidades das crias nas primeiras horas de vida (Alves \& Cox, 1999).

Em virtude da carência de dados científicos disponibilizados na literatura sobre a composição físico-química do colostro e do leite de transição, objetivou-se com este trabalho avaliar a influência da ordem de parto e do período de ordenha nas primeiras 24 horas pós-parto sobre a produção e composição do colostro e do leite de transição de cabras Saanen.

\section{Material e Métodos}

O experimento foi realizado no Setor de Caprinocultura do Departamento Agropecuário do Centro de Formação de Tecnólogos da Universidade Federal da Paraíba, Campus de Bananeiras/PB, nos meses de maio a outubro de 2002. A altitude local é de $552 \mathrm{~m}$ e a temperatura da região varia entre a máxima de $36^{\circ} \mathrm{C}$ e a mínima de $18^{\circ} \mathrm{C}$, com precipitação média de $1.200 \mathrm{~mm}$.

Foram utilizadas 41 matrizes da raça Saanen, em gestação, distribuídas em três grupos de acordo com a ordem de parto: 16 matrizes prímiparas; 17 matrizes de segunda parição; e oito matrizes de terceira ou mais parições. Esses animais foram acompanhados desde o segundo mês de gestação, com pesagens semanais até o parto.

As matrizes de segunda ou mais parições permaneceram gestantes e não lactantes por um período de 60 dias antes do parto.
Os animais foram alimentados duas vezes ao dia, às 8 e 16 h e receberam água à vontade, além de manejo sanitário, que foi igual para todos os animais. No terço final da gestação, os animais receberam dieta com feno de capimtifton como volumoso, balanceada para atender às exigências de mantença e gestação, segundo o AFRC (1993), com relação volumoso:concentrado 50:50. As sobras da dieta foram pesadas diariamente para ajuste da oferta de alimentos, permitindo-se $10 \%$ de sobras.

As amostras de colostro e do leite de transição foram coletadas da ordenha completa de todas as matrizes logo após o nascimento dos cabritos (zero hora), às 12 horas e às 24 horas após o parto. Retirou-se uma amostra homogênea em triplicata, representativa do colostro e do leite de transição, que foi congelada logo após a determinação do pH e da densidade, para as análises de acidez, gordura, extrato seco total e proteína total. As análises foram realizadas no Laboratório de Controle de Qualidade de Alimento da UFPB, Campus de Bananeiras - PB.

As análises para determinação dos teores de proteína foram realizadas utilizando-se o método Micro-Kjedhl, com o fator 6,38 multiplicado pela porcentagem de nitrogênio, métodos AOAC (1998). O teor de extrato seco total foi obtido pela secagem até peso constante, conforme método da AOAC, 925.23 (1998), e o teor de lipídios utilizando-se Lactobutirômetro de Gerber (AOAC, 1998). A densidade foi determinada por meio da leitura em termolactodensímetro a $15^{\circ} \mathrm{C}$ (AOAC, 1998). A acidez foi obtida por meio de titulação e determinada em graus Dornic ${ }^{\circ} \mathrm{D}$ (AOAC, 1998). A produção total das secreções lácteas até as 24 horas pós-parto foi determinada pelo somatório das três primeiras ordenhas: 0 (zero), 12 e 24 horas após o parto.

O delineamento experimental adotado foi inteiramente casualisado em parcelas subdividas no tempo, no qual o efeito da ordem de parição correspondeu às parcelas e as medidas repetidas no tempo às subparcelas. Os tratamentos foram compostos pela ordem de parição: 16 cabras de primeira parição (primíparas); 17 cabras de segunda parição; e oito cabras de terceira ou mais parições. Os efeitos da ordem de parto e do momento da ordenha sobre a produção, a composição, o pH, a acidez e a densidade do colostro e do leite de transição foram calculados por meio de análise de variância, segundo o modelo abaixo:

$$
Y_{i j k}=\mu+T_{i}+P_{j}+I_{i j}+E_{i j k}
$$

em que $Y_{i j k}=$ observação do indivíduo $\mathrm{k}$, pertencente ao tratamento i e ao período $\mathrm{j} ; \mu=$ média geral; $\mathrm{T}_{\mathrm{i}}=$ efeito do tratamento $\mathrm{i} ; \mathrm{P}_{\mathrm{j}}=$ efeito do período $\mathrm{j} ; \mathrm{I}_{\mathrm{ij}}=$ efeito da interação tratamento $\mathrm{i} \times$ período j; e $\mathrm{E}_{\mathrm{ijk}}=$ erro aleatório associado a cada observação $\mathrm{Y}_{\mathrm{ijk}}$. 
As médias obtidas foram submetidas ao teste Tukey, considerando o nível de 5\% de probabilidade, por meio do Sistema de Análise Estatística e Genéticas (UFV, 1982).

\section{Resultados e Discussão}

Não houve efeito $(\mathrm{P}>0,05)$ das ordens de parto sobre a produção de colostro pelas cabras (Tabela 1). As cabras de primeira parição, apesar de não terem alcançado o pleno desenvolvimento do úbere, apresentaram produção igual à daquelas de segunda e terceira ou mais parições. Goonewardene et al. (1999) observaram tendência $(\mathrm{P}<0,10)$ de maior produção de leite em cabras que progrediram da primeira para a segunda e a terceira parição.

Prasad et al. (2005), em pesquisa com cabras da raça Beetal e seus cruzamentos com animais da raça Jamunapari, Barbari e Black Bengal, verificaram diferença $(P<0,05)$ na produção de leite de animais de primeira cria $(797$ g) com animais de terceira cria (1001 g).

Não houve interação significativa ordens de parição $\times$ período pós-parto, por isso, os fatores foram avaliados isoladamente (Tabela 2). Nenhuma diferença $(\mathrm{P}>0,05)$ foi observada para o $\mathrm{pH}$, no entanto, em virtude da rápida mudança na sua composição, sobretudo nos teores de proteína e gordura, o colostro apresentou $(\mathrm{P}<0,05)$ maior

Tabela 1 - Produção de colostro e produção de leite de transição em cabras Saanen (litros/dia) de diversas ordens de parto

\begin{tabular}{lc}
\hline Ordem de parto & Produção \\
\hline $1^{\mathrm{a}}$ & $1,48 \mathrm{a}$ \\
$2^{\mathrm{a}}$ & $1,52 \mathrm{a}$ \\
$3^{\mathrm{a}} \mathrm{e}>3^{\mathrm{a}}$ & $1,71 \mathrm{a}$ \\
$\mathrm{CV}(\%)$ & 33,74 \\
\hline
\end{tabular}

Médias seguidas das mesmas letras não diferem entre si pelo teste Tukey a $5 \%$

Tabela 2 - Características do colostro e do leite de transição de cabras Saanen no momento de ordenha

\begin{tabular}{lcccc}
\hline Variável & \multicolumn{3}{c}{ Momento da ordenha } & \multirow{2}{*}{ CV (\%) } \\
\cline { 2 - 4 } & $0 \mathrm{~h}$ & $12 \mathrm{~h}$ & $24 \mathrm{~h}$ & \\
\hline $\mathrm{pH}$ & $6,47 \mathrm{a}$ & $6,51 \mathrm{a}$ & $6,58 \mathrm{a}$ & 3,44 \\
Acidez $\left({ }^{0} \mathrm{D}\right)$ & $46,1 \mathrm{a}$ & $28,8 \mathrm{~b}$ & $25,1 \mathrm{~b}$ & 25,14 \\
Densidade $\left(\mathrm{g} / \mathrm{cm}^{3}\right)$ & $1,053 \mathrm{a}$ & $1,031 \mathrm{~b}$ & $1,028 \mathrm{~b}$ & 1,28 \\
Gordura $(\%)$ & $8,29 \mathrm{a}$ & $6,10 \mathrm{~b}$ & $5,14 \mathrm{~b}$ & 29,0 \\
Extrato seco total (\%) & $23,60 \mathrm{a}$ & $15,02 \mathrm{~b}$ & $12,31 \mathrm{~b}$ & 27,70 \\
Proteína total (\%) & $9,24 \mathrm{a}$ & $5,38 \mathrm{~b}$ & $4,37 \mathrm{~b}$ & 30,90 \\
\hline
\end{tabular}

Médias seguidas das mesmas letras nas linhas não diferem $(P>0,05)$ entre si pelo teste Tukey. densidade $\left(1,053 \mathrm{~g} / \mathrm{cm}^{3}\right)$ em comparação ao leite de transição às $12\left(1,031 \mathrm{~g} / \mathrm{cm}^{3}\right)$ e 24 horas $\left(1,028 \mathrm{~g} / \mathrm{cm}^{3}\right)$ após o parto.

Diversas causas justificam a variação na densidade no leite, entre elas, a temperatura no momento da leitura da densidade, a temperatura do leite e a alteração da gordura e da composição do leite, ou seja, quanto maior o teor de sólidos no leite, maior a densidade (Prasad et al., 2002). Arguello et al. (2006), avaliando o efeito do número de lactações e do momento de ordenha após o parto em cabras da raça Majorera, verificaram valor em torno de $1,055 \mathrm{~g} / \mathrm{cm}^{3}$ no colostro dessas cabras, que, em 24 horas após o parto, reduziu para $1,040 \mathrm{~g} / \mathrm{cm}^{3}$.

Os teores de gordura e extrato seco total do leite diferiram $(\mathrm{P}<0,05)$ entre as ordens de parição e foram mais altos no colostro (8,29 e 23,60\%, respectivamente), no entanto, no leite de transição obtido às 12 e 24 horas pósparto não houve diferença significativa para essas características. Entre os componentes do leite, a gordura apresenta maior variabilidade e, de acordo com Folley \& Otterby (1978), varia consideravelmente entre raças e animais de mesma raça. Comportamento contrário foi encontrado por Arguello et al. (2006) de que conteúdo médio de gordura no colostro em fêmeas caprinas é menor ( $\mathrm{P}<0,05)$, em torno de $7,5 \%$, e aumenta para $9,0 \%$ no leite de transição 24 horas após o parto.

Os resultados da acidez obtidos no colostro diferiram $(\mathrm{P}<0,05)$ dos verificados nos leites de transição obtidos às 12 e 24 horas pós-parto. A maior acidez foi registrada na primeira ordenha, que apresentou alta correlação $(r=0,9)$ com o conteúdo de proteína, confirmando o pressuposto de Mariani et al. (1981) de que a menor porcentagem de proteína conduz a menor acidez titulável.

Considerando o momento da ordenha após o parto, comprovou-se que os teores de proteína total do leite mudam $(\mathrm{P}<0,05)$ após o parto. Os valores obtidos no momento do parto $(9,24 \%)$ foram elevados e apresentaram decréscimo significativo às 12 e 24 horas após o parto (5,38 e 4,37\%, respectivamente), mas não diferiu significativamente entre essas duas últimas ordenhas. Os resultados encontrados corroboram os obtidos por Chen et al. (1998), que observaram que o nível de proteína total no colostro e no leite de transição de cabras diminuiu bruscamente de $16,46 \%$ na parição para 9,10 e 7,68\% às 12 e 24 horas após o parto, respectivamente, e permaneceu estável (5,51\%) nos cinco dias seguintes ao parto. Portanto, no primeiro dia após o parto, houve redução de mais $50 \%$ no teor de proteína total, que foi principalmente causada pela concomitante redução do conteúdo $\alpha$-globulinas. 
Quiles et al. (1994), analisando a concentração de proteína total na secreção mamária de cabras após um dia do parto, observaram significativo decréscimo de 13\% no primeiro dia para $4,75 \%$ no quarto dia após a parição. $O$ decréscimo na concentração de proteína total na secreção mamária também foi evidenciado por Chen et al. (1999) ao analisarem amostras de leite de cabra. Esses autores observaram nível médio de $12 \%$ de proteína total no momento do parto e 4,2\% sete dias após o parto.

Ao parto, Csapo et al. (1994) registraram 16,2\% de proteína no leite de cabras Húngaras e Hadjjipanayiotou (1995) observou 16,0\% no leite de cabras Damascos e Chen et al. (1998) encontraram 16,5\% no leite de cabras Nubianas. Essas diferenças entre raças são mais evidentes na produção de leite - quanto maior a quantidade de leite ou de colostro produzido, menor a quantidade de proteína (Quigley et al., 1994).

Não foi observado efeito significativo da ordem de parto sobre as características do colostro e do leite das cabras, exceto o pH do colostro (Tabela 3).

A composição química do leite pode sofrer influência da alimentação, da genética, da sanidade e do volume de leite produzido pelo animal e provavelmente esses fatores também influenciam a composição do colostro. Como os animais em estudo apresentavam mesmo padrão genético, produção de colostro significativamente semelhante e mesmo manejo nutricional, a ordem de parto não influenciou significativamente a composição do colostro.

Prasad \& Sengar (2002), em experimento com cabras Barbari e seus cruzamentos, encontraram maiores níveis de sólidos totais $(15,8 \%)$ e gordura $(5,4 \%)$ em animais de primeira parição, enquanto o maior nível de proteína (3,8\%) foi encontrado em animais de segunda parição. Em ovelhas Del Belice, Cappio-Borlino et al. (1997) verificaram que o efeito da ordem de parto é significativo para a porcentagem de proteína e gordura.

O colostro de animais de terceira e mais parições apresentou pH maior $(6,70)$ que o obtido no colostro de animais

Tabela 3 - Características do colostro e do leite transição de cabras Saanen de diversas ordens de parição

\begin{tabular}{lcccc}
\hline Característica & \multicolumn{3}{c}{ Ordem de parto } & CV (\%) \\
\cline { 2 - 4 } & \multicolumn{1}{c}{$1^{\mathrm{a}}$} & $2^{\mathrm{a}}$ & $3^{\mathrm{a}} \mathrm{e}>3^{\mathrm{a}}$ & \\
\hline $\mathrm{pH}$ & $6,50 \mathrm{~b}$ & $6,46 \mathrm{~b}$ & $6,70 \mathrm{a}$ & 3,44 \\
Acidez ( $\left.{ }^{0} \mathrm{D}\right)$ & $34,53 \mathrm{a}$ & $33,00 \mathrm{a}$ & $32,29 \mathrm{a}$ & 25,14 \\
Densidade $\left(\mathrm{g} / \mathrm{cm}^{3}\right)$ & $1,037 \mathrm{a}$ & $1,038 \mathrm{a}$ & $1,038 \mathrm{a}$ & 1,28 \\
Gordura (\%) & $6,97 \mathrm{a}$ & $6,28 \mathrm{a}$ & $6,16 \mathrm{a}$ & 29,0 \\
Extrato seco total (\%) & $19,10 \mathrm{a}$ & $16,45 \mathrm{a}$ & $15,05 \mathrm{a}$ & 27,70 \\
Proteína total (\%) & $6,15 \mathrm{a}$ & $6,67 \mathrm{a}$ & $6,09 \mathrm{a}$ & 30,90
\end{tabular}

Médias seguidas das mesmas letras nas linhas não diferem $(P>0,05)$ entre si pelo teste Tukey. de primeira $(6,49)$ e segunda parição $(6,46)$. Esta diferença pode estar relacionada a diferenças no número de células somáticas do leite, que varia, entre outros fatores, com a idade do animal (Harmon, 1994). Os valores de pH encontrados nesta pesquisa foram próximos aos obtidos por Arguello et al. (2006), contudo, esses autores não verificaram diferenças $(\mathrm{P}>0,05)$ no $\mathrm{pH}$ do leite de cabras de primeira, segunda, terceira ou mais lactações.

\section{Conclusões}

A ordem de parto não influencia a produção nem a composição físico-química das secreções lácteas de fêmeas caprinas nas primeiras 24 horas após o parto, com exceção do $\mathrm{pH}$, ao passo que o momento de ordenha após o parto influencia a concentração dos constituintes lácteos.

\section{Literatura Citada}

AGRICULTURAL AND FOOD RESEARCH COUNCIL - AFRC. Energy and protein requeriments of ruminants. Wallington: CAB International, 1993. p.159.

ALVES, F.S.F.; COX, M. Colostro caprino e sua importância imunológica e nutritiva. Ciência Veterinária nos Trópicos, v.2, p.131-135, 1999.

ARGÜELlO, A.; CASTRO, N.; ÁlVAREZ, S. et al. Effects of the number of lactations and litter size on chemical composition and physical characteristics of goat colostrums. Small Ruminant Research, v.64, p.53-59, 2006.

ASSOCIATION OF OFFICIAL ANALYTICAL CHEMISTS - AOAC. Official methods of analysis. 16.ed., 4 rev., Washington: 1998. p.3-120.

CAPPIO-BORLINO, A.; PORTOLANO, B.; TODARO, M. et al. Lactation curves of valle del belice dairy ewes for yields of milk, fat, and protein estimated with test day models. Journal of Dairy Science, v.80, p.3023-3029, 1997.

CHEN, J.C.; CHANG, C.J.; PEH, H.C. et al. Serum protein levels and neonatal growth rate of Nubian goats kids in Taiwan area. Small Ruminant Research, v.32, p.153-160, 1999.

CHEN, J.C.; CHANG, C.J.; PEH, H.C. et al. Total protein and gglobulin contents of mammary secretion during early postpartum period of Nubian goats in the Taiwan area. Small Ruminant Research, v.31, p.67-73, 1998.

CSAPO, J.; CSAPO, Z.; MARTIN, T.G. et al. Composition of colostrum from goats, ewes and cows producing twins. International Dairy Journal, p.445-458, 1994.

FEITOSA, F.L.F.; BIRGEL, E.H.; CIARLINI, P.C. et al. Transferência de imunidade passiva colostral e a morbidade e mortalidade de bezerros neonatos. Revista Educação Continuada CRMV/SP, v.4, p.9-115, 2001.

FOLEY, J.A.; OTTERBY, D.E. Availability, storage, treatment, composition, and feeding value of surplus colostrum: a review. Journal of Dairy Science, v.61, p.1033-1060, 1978.

GOONEWARDENE, L.A.; OKINEA, E.; PATRICK, N. et al. The relationship between multiple births and milk yields in nonsuckled intensively managed dairy goats. Small Ruminant Research, v.32, p.181-185, 1999.

HADJIPANAYIOTOU, M. Composition of ewe, goat and cow milk and of colostrum of ewes and goats. Small Ruminant Research, v.18, p.255-262, 1995.

HARMON, R.J. Physiology of mastitis and factors affecting somatic cells counts. Journal of Dairy Research, v.77, p.2112, 1994. 
LAZZARO, J. [2002]. Dairy goat information of the serious kind. Supplementing colostrum Saanendoah. Disponível em: $<$ http://www.saanendoah.com/goatss.html.> Acesso em: 30/6/ 2002.

MARIANI, P.; PECORARI, M.; FOSSA, E. et al. Diffusione lel latte a coagulazione anômala e repporti com il contenuto celulare e L'acidità titolabile. Science Technology Latticinuous, v.32, p.222-232, 1981.

PARRISH, D.B.; WISE, G.H.; HUGHES, J.S. et al. Properties of the colostrums of the dairy cow. V. Yield, specific gravity and concentrations of total solids and its various components of colostrums and early milk. Journal of Dairy Science, v.33, p.457-462, 1950.

PRASAD, H.; SENGAR, P.S. Milk yield and coxmposition of the Barbari goat breed and its crosses with jamunapari, Butal and black Bengal. Small Ruminant Research, v.22, p.1-5, 2002.
PRASAD, H.; TEWARI, H.A.; SENGAR, O.P.S. Milk yield and composition of the beetal breed and their crosses with Jamunapari, Barbari and Black Bengal breeds of goat. Small Ruminant Research, v.58, p.195-199, 2005.

QUIGLEY, J.D.; MARTIN, K.R.; DOWLEN, H.H. et al. Immunoglobulin concentration, specific gravity, and nitrogen fractions of colostrum from Jersey cattle. Journal of Dairy Science, v.77, p.264-269, 1994.

QUILES, A.J.; GONZALO, L.; FUENTES, F. et al. Protein quality of Spanish Murciano-Granadina goat milk during. Small Ruminant Research, v.14, p.67-72, 1994.

EYCLYDES, R.G. Sistema de Análise Estatísticas e Genéticas SAEG. Viçosa, MG: Universidade Federal de Viçosa, 1982. 59p.

WATERMAN, D. [1998]. Colostrum: the beginning of a successful calf raising program. Disponível em: <http://www.dqacenter.org/ university.// Acesso em: 2/11/2002. 